with petechial spots on the abdomen, and the patient became very comatose and drowsy. On April 24th she became quite unconscious, and died about 3.15 P.M. There appeared to be a good deal of local inflammation in the site of the growth, and shortly before death petechiæ appeared upon the face.

The Characters of thr Fluid used for InJection.

It may be here especially noted : (1) That the fluid was cultivated by Dr. Slater, and proved sterile. (2) That just after the last injection an injection of equal magnitude was made in a case of carcinoma, with but slight effects; the fluid was taken from the same bottle. (3) The fluid was obtained from the British Institute of Preventive Medicine and was prepared by mixing the toxins of erysipelas and the bacillus prodigiosus. It was twice cultivated and found to be sterile.

The general treatment of the case may thus be summarised. Stimulants were freely given, and the patient's general health well supported. When the serious symptoms appeared towards the close of the case, cold sponging was resorted to to attempt to reduce the hyperpyrexia, and at the last, when respiratory embarrassment became evident, liquor strychninæ was administered. The injections were carried out with the same syringe, always carefully sterilised by boiling before use.

\section{Summary OF RESUlts.}

A summary of the symptoms observed in this case would be as follows: Smart reaction followed the first two injections. After that three injections made in increasing quantities failed to have effect. After a week's interval severe reaction was again established. The effect on the growth injected was certainly very marked. It caused its undoubted shrinkage and apparent disappearance. This seemed due purely to inflammatory action in a soft neoplasm, rather than to any purely specific action of the fluid itself. The fatal end of the case will be discussed after the post-mortem appearances are described.

Post-mortem Appearances.

At the post-mortem examination, conducted by Dr. Rolleston, signs of general pyæmia were apparent. Thus secondary abscesses and infarcts were found in the liver, myocardium, kidneys, and right knee-joint. The growth beneath the clavicle was necrotic, and it was particularly important to note that beneath the site of the two nodules which had disappeared was some purulent infiltration of the thoracic muscles. A bacteriological examination was kindly performed by Dr. Russell Wells, and the staphylococcus aureus was found in the secondary. abscesses. This is noteworthy, as the original fluid was prepared from streptococci. There were no visceral deposits of sarcoma.

RemarKs.

I have thought it right to record this case because it well illustrates the difficulties and dangers that attend methods of treatment the effects of which may. easily spread beyond our control. : Fortunately in this case the serious nature of the disease justified the employment of a perilous mode of treatment. The patient could not long have survived, but it is right to allow. that her life was undoubtedly shortened by the treatment. Nevertheless, so marked was the effect produced upon the prominent masses of growth that I would not hesitate to advise this treatment in cases of sarcoma which appear hopeless for less risky modes of treatment. It is especially interesting to note that the same fluid, in the same doses, was used for another patient suffering from carcinoma with little or no reaction result. The injections were made with scrupulous care, with an aseptic syringe, under my immediate direction. The fluid was found to be sterile. Hence the fatal organisms probably developed in the necrosing tissues of the growths themselves, and the "flaw" in this case was possibly due to imperfect disinfection of the skin. Little has hitherto been done with the seropathy of malignant growths in this country. From America we have the most conflicting testimony. For instance, Professor Senn ${ }^{1}$ reports nine cases of failure, and says that the method is of no value. whereas the successful results claimed by Coley are well known, ${ }^{2}$ and some of his cases are truly remarkable. An excellent paper by Repin ${ }^{3}$ well sets forth the present status of the serum treatment of these cases. There can be no doubt that remarkable results in the disappearance of sarcomata have been brought about by some of these surgeons. Butlin, in a clinical lecture delivered at St. Bartholomew's Hospital on December IIth, 1895 , seemed to think that the method was useless in carcinoma, but might prove of some benefit in sarcoma. The method is worthy of more extensive trial in this country, and the case I have related shows the importance of making every attempt, at all events, to prevent the entrance of dangerous organisms into the inflamed neoplasms.

Dr. Slater, our bacteriologist at St. George's Hospital, to whom I am indebted for much information on this subject, thus classifies the agents at present employed :

(a) Injection with the virulent organism apparently effective, but certainly dangerous.

(b) Treatment with toxins, occasionally successful, but giving rise to very severe symptoms.

(c) Treatment with the toxic blood serum of an infected animal, of doubtful efficacy, but giving rise to less constitutional disturbance.

(d) Antitoxic serum, free from risk, but apparently ineffective.

Thus it would appear that the more virulent the fluid the more marked is the effect upon neoplasm, and curative action in the growth and danger to life are in direct proportion. This is only what one would from analogy expect. It is after smart and dangerous attacks of erysipelas that retrogression of malignant growths has been observed most strikingly, and which led to the experiments of Ricord and Fehleisen, who in 1882 attempted to inoculate with living cultures of erysipelas.

I have received the following note on the preparation of Coley's fluid from Professor Macfadyen :

"Flasks containing nutrient broth are inoculated with a virulent culture of the streptococcus erysipelatis, and incubated at $30^{\circ}$ to $35^{\circ} \mathrm{C}$. for three weeks. The same flasks are then inoculated with the bacillus prodigiosus, and kept at room temperature for ten to twelve days. The mixed culture obtained is heated up to $50^{\circ}$ or $60^{\circ} \mathrm{C}$., with a view of killing the micro-organisms. A small quantity of carbolic acid is added to the sterilised broth, and it is used without filtration, commencing with small hypodermic doses of not more than half a minim."

1 Journal Amer. Med. A $8^{\circ} 0 c$.. July 2.th, 1895. 2 Amer. Journ. Med. Sci., July, 1894. 3 Revue de Chirurgie, June, 1895

\section{ON THE ACTIVE CONSTITUENT OF THE THXROID GLAND.}

By ROBERT HUTCHISON, M.D.,

Late Chemical Assistant to the Professor of Physiology, University of Edinburgh.

A few months ago I published in the Journal, ${ }^{1}$ a preliminary note, in which I stated that the colloid matter of the thyroid is the only active part of the gland therapeutically. Since then I have published in the Journal of Physiology, ${ }^{2}$ a paper dealing fully with the chemistry of the thyroid in which the above conclusion is supported by evidence drawn from the results of experiments upon dogs. In the present article I wish to present the clinical evidence by which I believe my conclusions to be finally proved.

For the sake of clearness it will be well to begin with a brief summary of the chief facts in the chemistry of the thyroid. I have shown that the proteids of the gland are two in number :

1. A nucleo-albumin present in small amount, and probably derived from the cells lining the acini.

2. The colloid matter, which possesses certain striking chemical peculiarities. One of these is that it contains, in addition to phosphorus, a considerable quantity of iodine. Another is that on gastric digestion it readily splits into two parts-a proteid part which yields albumoses and peptone, and a small insoluble residue which is entirely proteid free.

1 BRITISH MedICAT JOURNAL, March 2ist, 1896.

2 Journal of Physiology, vol. xx, p. 474 . 
Most of the iodine and all the phosphorus of the original colloid is found in this non-proteid residue, but the albumoses and peptones derived from the proteid part are also found to retain a small amount of iodine in their constitution.

The extractives of the thyroid (creatin, xanthin, etc.) resemble those of other organs, but they are said (by Fraenkel and Drechsel) to include amido bodies, hitherto unknown, to which an important part in the activity of the gland is to be ascribed.

In order to test the chemical activity of these different ingredients I isolated them.

The Colloid Matter.-A dilute alkaline extract of the fresh glands was made. The colloid matter was precipitated from this by the addition of acetic The colloid matter was precipitated from this by the addition of acetic acid, and purified by reprecipitation and washing with alcohol

It forms a very pale-brown powder, devoid of taste or odour. rated on the water bath, and any traces of proteid (serum, albumen, etc.) which separated out were removed by filtration. The residue was neutralised, made up to a definite bulk, and preserved by the addition of a few drops of chloroform. It forms a yellowish fluid, with a taste like that of dilute beef juice. This contains all the extractives of the gland, including the bodies described by Fraenkel and Drechsel.

Nucleo-albumin.-I also prepared. a small amount of nucleo-albumin by Halliburton's method. It formed an almost colourless powder when purified and dried.

\section{The Specific Action of the Thyroid.}

How are we to know whether any of the above preparations are active? This necessitates the further question, What is meant by the activity of the thyroid? With this question, What is really the pharmacology of the thyroid? I propose to deal fully in another paper, but at present one may say briefly that the specific action of the thyroid consists in a stimulation of general metabolism and an increase in the oxidation processes of the body. Clinically these effects are manifested by progressive loss of weight, slight rise of temperature and pulse, and an increased output of nitrogen and carbonic acid. If a preparation is capable of producing these symptoms in a healthy individual, it is to be regarded as "active." It will be observed that I do not include in the above list of symptoms those subjective phenomena such as headache and pains in the limbs, which help to make up the picture of what is known as "thyroidism," or over-action of the thyroid. I omit them because one cannot be sure a priori that these are not merely accidental concomitants which would not manifest themselves if one were really dealing with the active part of the gland alone and in a pure state. To this question, however, I shall return later. It is a commonplace of clinical observation that individuals vary very greatly in their reaction to the thyroid. In some all the above effects can be produced by the administration of quite small doses of the gland, in others large quantities can be given with little or no result. Accordingly, in testing the above preparations, I always made sure that the patient really reacted distinctly to moderate quantities of the whole gland before drawing any conclusions regarding the activity or the reverse of the particular preparation under trial. For this reason it is more satisfactory to deal with cases of myxœdema, whose reaction to thyroid treatment is so very marked. I have been fortunate enough to have three well-marked examples of that disease on which to try the preparations.

As I have shown above, there were three preparations which one wished to test: (I) A solution of the extractives of the thyroid-using that term to include all the non-proteid constituents of the gland; (2) the pure colloid matter; (3) the nucleo-albumin.

\section{(1) The Extractives.}

These may be dismissed briefly. I have administered them both to normal subjects, whose reaction to the whole gland was well marked, and also to cases of myxcedema. The quantity given amounted in some cases to the equivalent of $30 \mathrm{~g}$. of the fresh gland daily-(roughly = the thyroids of five sheep). In no case did I find any symptoms at all produced. Patients who had been progressively losing weight on the fresh gland began immediately to gain weight when put on the extractives. There was no rise of temperature or pulse, and no subjective symptoms were complained of. Cases of myxœdema remained in statu quo. One might, in fact, have just as well been administering beef tea. I thereforeconclude that the active constituent of the thyroid is not among the extractives. Inasmuch also, as the solution was so prepared that it would contain Fraenkel's "thyrecantitoxin" I conclude that that substance is not the cause of the activity of the thyroid as administered therapeutically.

\section{(2) The Pure Colloid Matter.}

The amount of this substance yielded by the fresh giand. varies considerably, but on an average $10 \mathrm{~g}$. of fresh gland yields rather more than I g. of dried colloid. I administered it always in the form of a powder. The usual dose employed was $0.1 \mathrm{~g}$. This may be regarded as approximately equal to Io gr. of fresh gland, or to two of the ordinary thyroid tabloids. I found this substance to be invariably active. It produced all the ordinary signs of thyroid activity in healthy individuals, and in large doses distinct " thyroidism" resulted in some cases. I shall, however, only give the details of its action in one case-a well-marked case of myxœdema treated entirely by the pure colloid matter, and with a very brilliant therapeutic resnlt. For this case $I$ am indebted to the kindness of Dr. Inkster, Edinburgh. The notes were made for me by my friend Dr. George Elder, under whose observation the patient remained throughout the treatment.

Mrs. M. aged 55. About fifteen years earlier she had been exhausted by repeated childbirths. She then noticed some thickness of her voice, followed by swelling of the hands and face, loss of hair, weakness, and feeling of coldness. The symptoms gradually progressed till June, $18 \% 6$, when she presented the typical appearance of a well-marked case of myxoedema. Hebetude was marked. There was much swelling of sub. cutaneous tissues, large areas of baldness on the scalp, dryness and coldness of skin, typical slow speech. Her appearance at this time is shown in the accompanying (illustration (Fig. I). All the viscera were

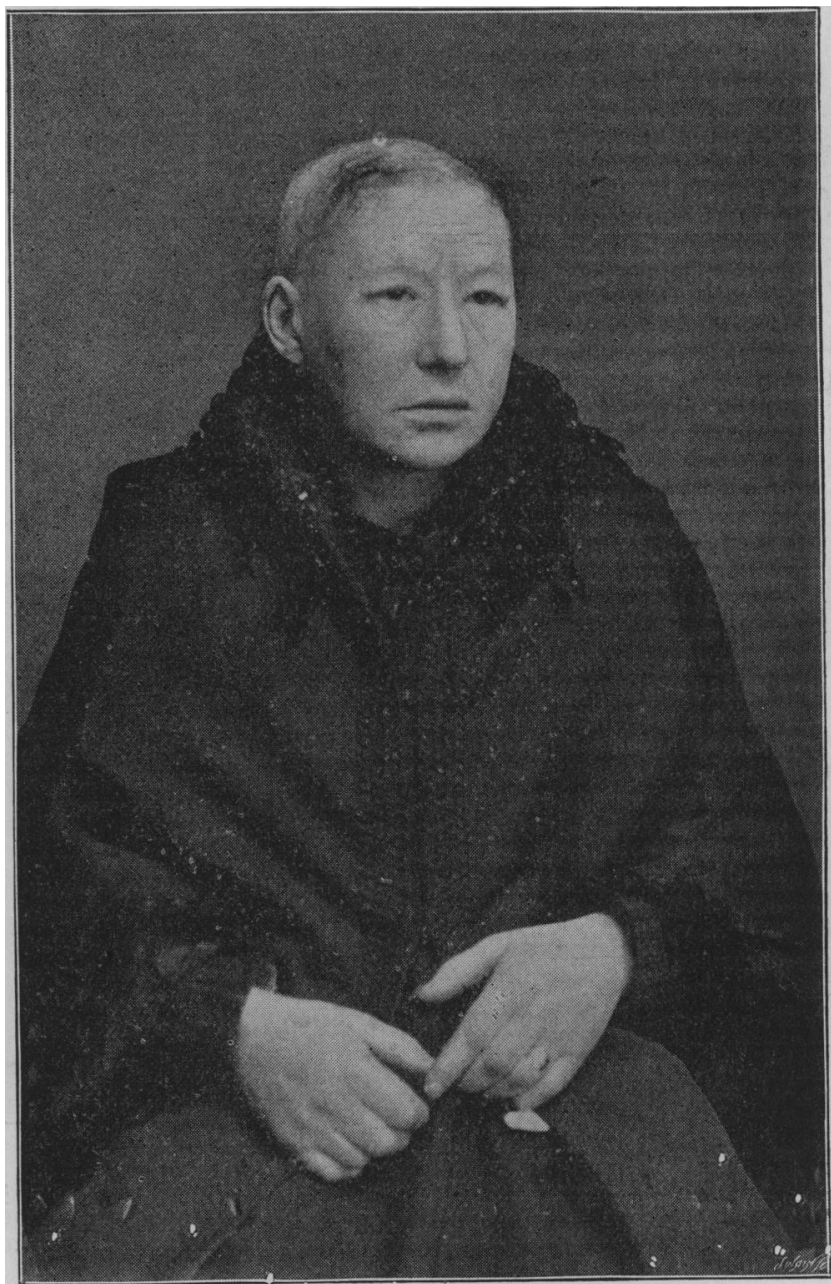

Fig. 1.-Before treatment.

healthy. Her weight befnre the commencement of treatment was io $\mathrm{s}$ $9 \mathrm{lbs}_{2} ;$ the pulse rate was 60 in $n$ the temperature subnormal 


\section{Progress.}

On June rath treatment was begun with one powder of $0.05 \mathrm{~g}$. (about $\frac{1}{g r}$.) of pure colloid matter. This was given at noon; in the evening the pulse rate was 76 and the temperature $97.8^{\circ} \mathrm{F}$. June ruth. Two of the above powders daily; patient was perspiring and

June ${ }_{15}$ th. Three powders; the temperature in the evening was $100.3^{\circ} \mathrm{F}$., pulse 88.

June r6th. Two powders; some headache and pains in the limbs, worst one hour after porvders; she thought her tongue felt "smaller," and speech was already more brisk ; the skin was moist, temperature normal, pulse roo.

June 27th. Since the last note she had had a powder thrice daily; improvement had gone on rapidly.

July ist to r5th. Four powders daily. Temperature, average $99.2^{\circ} \mathrm{F}$;

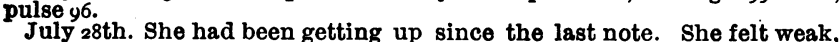
with pains in the limbs and a tendency to cedema of the ankles on standing. She was noticeably thinner. A good deal of desquamation was going on, and fine hairs have begun to appear on the bald places. She began to take o.r g. colloid daily.

August r2th. The change in the face was now very remarkable. The features were thin and sharp, the skin soft and moist. The pulse was 80 , the temperature normal. The hair a quarter of an inch long; the weight 9 st. 4 lbs.

September 28th. She was still progressing rapidly. She felt quite strong and well. Hair one inch long. To continue o.r g. colloid daily.

The condition of the patient at the present time (November 15 th) is shown in the accompanying illustration (Fig. 2). Her weight is now 8 st. $12 \frac{1}{1 b s}$. - nearly 2 st. less than at the commencement of treatment.

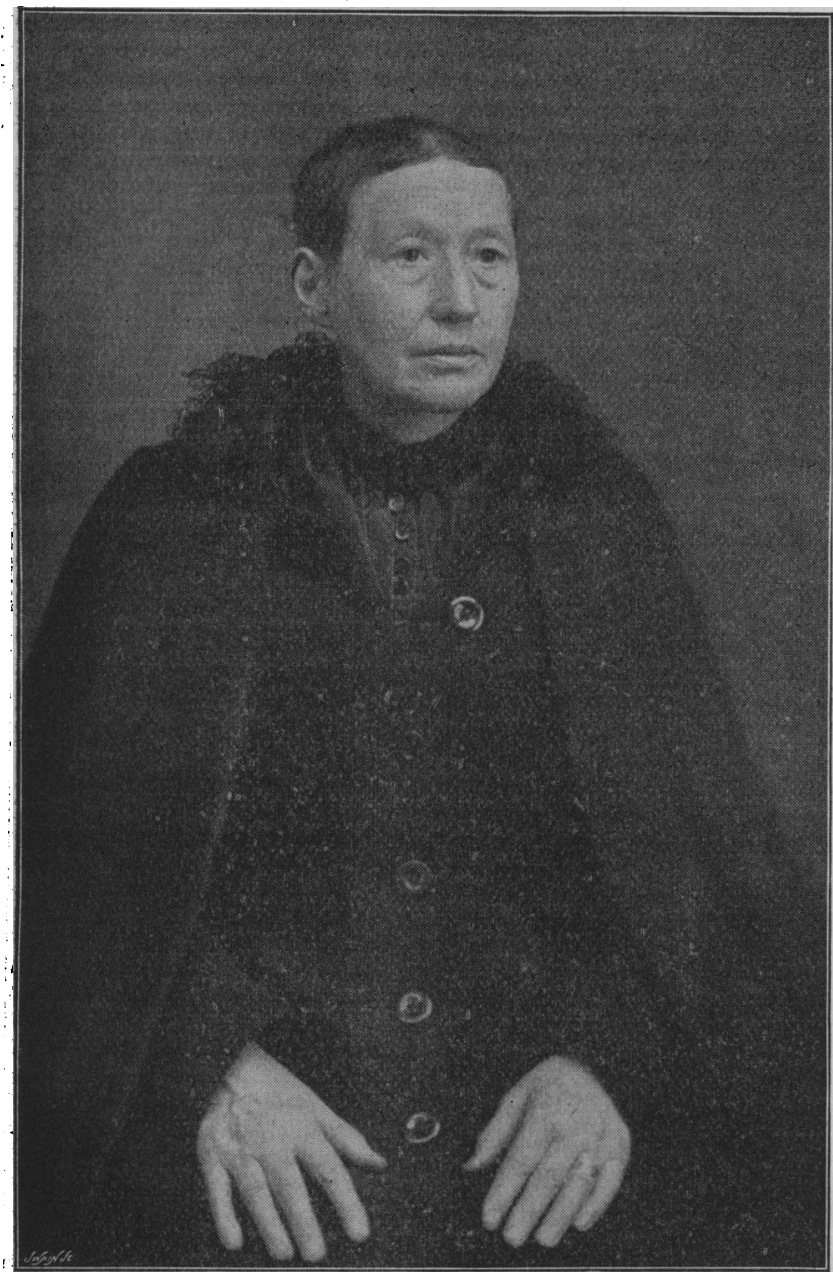

Fig. 2.-Mrs. M. after five months' treatment with " colloid."

From the effect on this case there can be no shadow of a doubt that the colloid matter is active. It acted rapidly and effectively, it was extremely well borne, and at no time did the dosedexceed $0.2 \mathrm{~g}$. (= 3 gr.) daily.

The Constituents of the Colloid Matrer. It is not enough, however, to , have" shown that the colloid matter is active as a whole. I have already pointed out that the colloid is to be regarded as a compound substance which can be very readily split up into a proteid and a non-proteid part. Does the colloid owe its activity to one of these constituents only or do both participate in the action? If so, what is the part played by each? In order to solve these problems, I took some of the pure colloid matter, submitted it to gastric digestion for several hours, and separated the proteid and non-proteid constituents in a manner described in detail elsewhere. The non-proteid body formed a dark brown powder, odourless and tasteless; $25 \mathrm{~g}$. of colloid yielded $0.9 \mathrm{~g}$. of the substance. The proteid constituent was in the form of albumoses ; these formed a colourless, somewhat hygroscopic powder with a bitter taste; $25 \mathrm{~g}$. colloid yield 12 of albumoses.

The Proteid Constituent of the Colloid.

Is the proteid constituent of the colloid (that is, in this case the albumoses) active?

I tested the albumoses prepared as above on the following case of myxœdema, for which I am indebted to the kindness of Dr. J. O. Affleck, Edinburgh.

W. R., plumber, aged 54 , complained of swelling of the face and hands, slowness of speech and apathy ; duration, 7 months. On June roth, 1896 . the patient exhibited the symptoms of distinct but not advanced myxœedema. Swelling was well marked in the face, the skin was dry, the speech characteristic ; there was no loss of hair. The temperature was subnormal, the pulse 9o, the weight ro st. 12 lbs., viscera normal.

\section{Progress.}

June i6th. Began o.rg. of pure albumoses morning and evening.

June 28 th. The weight had fallen to ro st. 10 1 lbs. ; no other symptoms.

July 6 th. Since the last note he has been having 0.1 g. thrice daily; the weight was ro st. $8 \mathrm{lbs}$. He had occasional shooting pains in the arms, the pulse was $1^{12}$, the temperature normal.

July rath. During the last week he had had o.4 g. daily; the weight was. ro st. 4 lbs. He had had pains in limbs and headache that week. The rost. 4 lbs. He had had pains in limbs

July roth. Since the last note the treatment had been stopped. The weight had risen to ro st. $8 \mathrm{lbs}$. The pulse was 80 , and the temperature subnormal.

August 2 nd. Since July 20 th he had had o.15g. albumoses morning and evening. The weight was ro st. 5 lbs. ; the pulse was ros.

September roth. The face was certainly less swollen, speech quicker, and he felt well. The weight was rost. $5^{\frac{3}{4}} \mathrm{lbs}$. The albumoses were stopped.

September igth. The weight was rost. $8 \frac{1}{2} \mathrm{lbs}$

September 20 th. He was ordered $0.05 \mathrm{~g}$. of the non-protoid part of the colloid instead of the albumoses twice a day.

September 26th. The weight had fallen to ro st. 5 lbs. The non-proteid was stopped.

October 3 rd. The weight was rost, $4 \mathrm{lb}$. Puffiness of the face had quite disappeared, speech was almost normal, and the patient felt quite himself again.

From the result of this case we are able, I think, to answer in the affirmative the question as to the activity of the proteid constituent of the colloid matter. At the same time the activity is by no means the same as that of the colloid as a whole. Larger doses of the substance were required to. produce a noticeable effect. Thus the patient was taking on an average during the treatment a daily amount of albumoses which would be derived from about $6 \mathrm{~g}$. of the fresh gland, which is a very considerable quantity, representing as it does about eighteen of the ordinary tabloids. The action of the albumoses differs also from that of the colloid as a whole in being more transitory. As soon as their administration is stopped the patient's weight returns to its former amount. The albumoses would seem to be more rapidly got rid of in the tissues than the colloid as a whole; the latter seems to be fixed by the tissues, and to have therefore a cumulative action, while the albumoses are rapidly excreted.

The Non-Proteid Part of the Colloid.

I have not considered it necessary to put this part of the colloid to any elaborate clinical tests. The reasons for this are given in the article to which I have already referred. As I have there shown the non-proteid part of the thyroid is without doubt the substance from which is derived Baumann's thyroiodin, or iodothyrin, as it is now called. Now as to the activity of the latter substance there is no room for any doubt. It has been abundantly proved by Roos ${ }^{3}$ in cases of simple goître, and by Ewald ${ }^{4}$ and others in myxœdema. More than this, the substance is active in very minute doses.

${ }^{3}$ Zeitsch.f. phys. Chemie, xxii, p. 16, 1896. Verhandlungen des 14ten Cong.f. inn iMed., 1896, p. Iог. 
In the second case of myxœdema recorded above it will be noted that for one week (September 2oth to 27th) the patient got, instead of the albumoses, $0.05 \mathrm{~g}$. of the non-proteid body twice daily. During this week he lost nearly 3 lbs. in weight, a much greater loss than had been brought about by a considerably larger quantity of the albumoses. Further than this the loss of weight continued for a week after the administration of the substance was stopped; in other words, it has that prolonged action which is characteristic of the colloid as a whole, which is absent in the case of the albumoses.

It would appear, therefore, that the colloid matter owes its activity chiefly to its non-proteid part-that is to say, to the part of it which is richest in iodine. The objection may be raised that the albumoses, as I have prepared them, owe their activity to the incomplete separation from them of the non-proteid body. Inasmuch, however, as I have submitted specimens of the albumoses to a three hours' boiling with 10 per cent. sulphuric acid, and subsequent extraction for three times with boiling alcohol, and have found them still to contain iodine, I hardly think that the objection is valid.

The Nucleo-Albumin.

I have administered this substance in one case of exophthalmic goître, which reacted markedly to ordinary thyroid treatment. The dose given was small but not disproportionate to the small amount of the substance present in the gland. Its administration was continued for a week but no evidence of activity was observed.

The Therapeutic Activity of the Colloid M.atter.

From these observations it follows that the total therapeutic activity of the thyroid is to be attributed to the colloid matter. On consideration it will be found, I think, that all the preparations of the thyroid which have been found to be of therapeutic value contain the colloid. It goes into solution in all watery and glycerine extracts. Of dried preparations of the whole gland it is, of course, unnecessary to speak. One preparation deserves special mention-the thyroid powder prepared by White. ${ }^{5}$ This powder was prepared in the manner usually employed for the separation of ferments, and was successfully used in some of the earliest cases of myxœdema treated by the thyroid. As a result, the conclusion was arrived at by many that the thyroid owes its activity to the presence of a ferment. I have found, however, on preparing the powder according to the directions of White, that the colloid matter is thrown down along with the precipitate of calcium phosphate, and that the dried powder consists, in fact, of calcium phosphate and colloid matter. It is, therefore, not surprising that it should have been found to be active. Vermehren ${ }^{6}$ has described a case of cretinism cured by the administration of the precipitate produced by the addition of alcohol to a glycerine extract of the thyroid. Of course, such a precipitate would contain all the proteids of the gland, including the colloid matter.

The Therapedtic Advantages of the Colloid Matrer.

Seeing, then, that all the preparations of proved activity contain the colloid matter, the time has come, I think, when we should reconsider our methods of thyroid administration, and give to patients the colloid matter separated from the inert parts of the organ in a state of purity. The advantages of such a mode of administration are obvious.

1. Constancy of dose is ensured. The quantity of colloid present in different glands varies considerably; hence the amount of active substance in dried preparations of the whole gland is really not constant. By isolating the active part and giving it alone the difficulty is removed.

2. The drug is quite pure. The pure colloid matter is entirely free from fat, which is always present in dried preparations of the whole gland and is apt to make such preparations disagree when given in large doses.

3. The pure colloid is entirely free from taste and odour and keeps indefinitely. These advantages cannot be claimed for other thyroid preparations.

4. A very small dose is required. Thus it will be found that as much of the dried colloid as will lie upon a sixpence

5 BRITISH ME ICAL JOURNAL 1892, vo ii, p. 966, and Pharm. Journ., September and, r893.

${ }^{6}$ De med. Woch., March it th, 1893. is equivalent in activity to three of the tabloids in common use.

5. The colloid is absorbed with great ease and rapidity. This is a point on which I desire to lay special emphasis. Incredible though it may seem, I have seen its effects begin to be manifested in a thyroidectomised dog within five minutes of its administration by the mouth.

6. The administration of the colloid matter is really the most economical way of giving the thyroid. In giving the colloid, one is giving the active part of the glands, nothing more and nothing less. There is no waste of active material such as occurs in the preparation of thyroiodin.

\section{The Subjective Symptoms.}

Are the subjective symptoms such as headache and pains in the limbs which are so often complained of by patients who are being treated by large doses of ordinary thyroid preparations produced also when the pure colloid is given? In other words, are these symptoms a necessary result of giving large doses of the active principle of the thyroid, or are they merely by-effects due to the presence of impurities in the preparation employed? My own observations show quite clearly that such symptoms are unavoidable results of the physiological action of the gland whenever that action is pushed beyond a certain limit. These symptoms are produced whenever large doses are given, even if everything other than the active principle of the gland be excluded from the preparation. It cannot, therefore, be fairly claimed for the colloid or for any other thyroid preparation that it obviates the occurrence of such symptoms. At the same time, the advantages of giving the colloid matter isolated in a pure state are so obvious that I have asked Messrs. Oppenheimer and Co., wholesale chemists, to prepare it according to my directions. This they have done, and members of the profession can now obtain the substance in a convenient and reliable form for administration to patients.

\section{REMARKS ON THE OPERATIVE TREATMENT OF A CASE OF} DOUBLE FRONTAL SINUS EMPYEMA, COMPLICATED BY DOUBLE ANTRAL SUPPURATION.

BY HERBERT TILLEY, M.D., B.S.(LOND.), Assistant Surgeon, London Throat Hospital.

IF one was asked what kind of surgical diseases (except those of a malignant nature) are most intractable to treatment, and fraught with most anxiety to the surgeon as to the ultimate success of his intervention, it is probable that the correct answer would refer to certain cases of chronic suppuration of the various hard-walled, bony cavities of the body.

The following case may therefore be of interest both to the general surgeon as well as to those who give special attention to rhinology, and this not only because of the extent and duration of the disease, and the number of accessory cavities involved, but also because the treatment which has been practically successfnl embodies most of the suggestions for dealing with chronic suppuration of the frontal sinuses which have been made up to the present time:

Mr. S., aged 38, was sent to me, October $19 t h$, by his medical attendant on account of a constant purulent discharge from the nose, which he found associated with polypi. The discharge had been continuous for eighteen years, except for slight remissions during sea voyages. When about 8 years of age he had a severe blow on the forehead, after which he had a discharge from the nose, but whether purulent or not he cannot remember. When is years old he was attacked with violent frontal headache and fever, and a large abscess formed over the lower part of the forehead, and the whole scalp became tender and swollen. The abscess was opened by a median vertical incision extending from the root of the nose about 2 inches upwards, and counter-openings were made at different parts of the scalp where drain tubes were inserted. He was confined to bed for some six weeks, and when sufficiently strong he left for South Africa, where for five years a 